\title{
Radioactivity in Trinitite six decades later
}

\author{
Pravin P. Parekh ${ }^{\mathrm{a}, 1}$, Thomas M. Semkow ${ }^{\mathrm{a}, \mathrm{b}, *}$, \\ Miguel A. Torres a, Douglas K. Haines ${ }^{a}$, \\ Joseph M. Cooper ${ }^{b}$, Peter M. Rosenberg ${ }^{\text {a }}$, \\ Michael E. Kitto ${ }^{\mathrm{a}, \mathrm{b}}$ \\ a Wadsworth Center, New York State Department of Health, P.O. Box 509, Albany, NY 12201, USA \\ ${ }^{\mathrm{b}}$ University at Albany, State University of New York, Albany, NY 12201, USA
}

Received 1 September 2004; received in revised form 1 January 2005; accepted 1 January 2005

Available online 15 August 2005

\begin{abstract}
The first nuclear explosion test, named the Trinity test, was conducted on July 16, 1945 near Alamogordo, New Mexico. In the tremendous heat of the explosion, the radioactive debris fused with the local soil into a glassy material named Trinitite. Selected Trinitite samples from ground zero (GZ) of the test site were investigated in detail for radioactivity. The techniques used included $\alpha$ spectrometry, high-efficiency $\gamma$-ray spectrometry, and low-background $\beta$ counting, following the radiochemistry for selected radionuclides. Specific activities were determined for fission products $\left({ }^{90} \mathrm{Sr},{ }^{137} \mathrm{Cs}\right)$, activation products $\left({ }^{60} \mathrm{Co},{ }^{133} \mathrm{Ba},{ }^{152} \mathrm{Eu},{ }^{154} \mathrm{Eu},{ }^{238} \mathrm{Pu},{ }^{241} \mathrm{Pu}\right)$, and the remnants of the nuclear fuel $\left({ }^{239} \mathrm{Pu},{ }^{240} \mathrm{Pu}\right)$. Additionally, specific activities of three natural radionuclides $\left({ }^{40} \mathrm{~K},{ }^{232} \mathrm{Th},{ }^{238} \mathrm{U}\right)$ and their progeny were measured. The determined specific activities of radionuclides and their relationships are interpreted in the context of the fission process, chemical behavior of the elements, as well as the nuclear explosion phenomenology. (C) 2005 Published by Elsevier Ltd.
\end{abstract}

Keywords: Trinitite; Trinity test; Fission products; Plutonium isotopes; Manmade radioactivity

\footnotetext{
* Corresponding author. Tel.: +1 518474 6071; fax: +1 5184748590 .

E-mail address: tms15@health.state.ny.us (T.M. Semkow).

${ }^{1}$ Principal author, retired.
} 


\section{Introduction}

The first nuclear-weapon test, and the first manmade nuclear explosion, was conducted on July 16, 1945, on the White Sands Missile Range near Alamogordo, New Mexico. The test, called the Trinity test, was a part of the World War II Manhattan project started three years earlier. The core of the nuclear device, named Gadget, was ${ }^{239} \mathrm{Pu}$ obtained from the Hanford production complex in Washington State. The Gadget was raised to the top of a 100-foot steel tower positioned at ground zero (GZ) and exploded successfully at 5:29:45 a.m. The observations made then are well-documented (Storms, 1965; Bainbridge, 1976; Szasz, 1984; Rhodes, 1986). The explosive yield of the test was estimated at $21 \mathrm{kT}\left(1 \mathrm{kT}=10^{12} \mathrm{cal}\right.$; US DOE, 2000).

The steel tower vaporized in the tremendous heat generated from the explosion. The temperature at GZ was estimated to be greater than $1470{ }^{\circ} \mathrm{C}$ (Ross, 1948). As a result, the desert sands that were mixed with the device radioactive debris melted and formed a green glassy substance upon cooling (see Fig. 1). Enrico Fermi described the site as "a depressed area 400 yards in radius glazed with a green, glasslike substance where the sand had melted and solidified again" (Storms, 1965). The glassy formation was termed 'Trinitite'. A detailed microscopic study revealed that Trinitite contained two distinct types of glass, one formed from the feldspar and

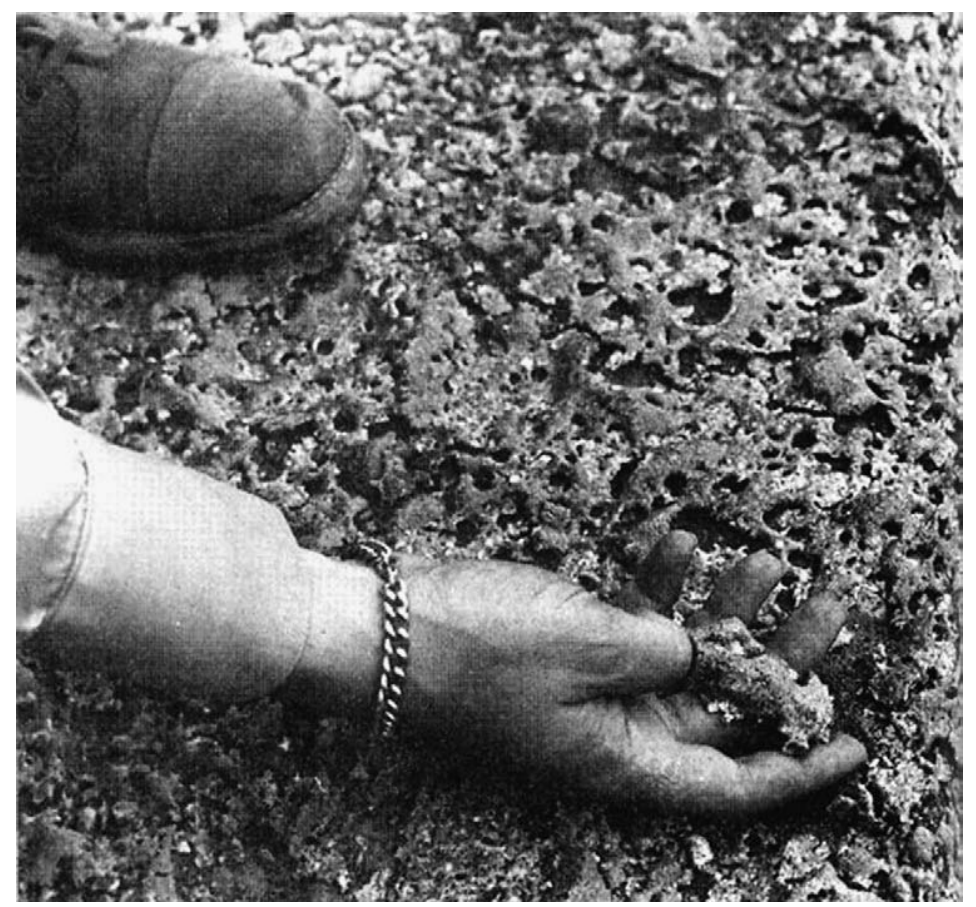

Fig. 1. Original Trinitite after the explosion (courtesy of C. Sublette, http://nuclearweaponarchive.org). 
clay in the sand, and the other from quartz in the sand that fused directly into silica glass (Ross, 1948). Much of the Trinitite was removed from the site by the Atomic Energy Commission in 1952, and buried (US GPO, 2000). Only small pieces of Trinitite remained onsite.

The Trinity site was declared a national historic landmark in 1975 . Today, the site is enclosed by two fences (Hansen and Rodgers, 1985; US GPO, 2000). The outer fence is circular, with a radius of about $500 \mathrm{~m}$. The inner, oblong fence has a distance from GZ ranging from 65 to $150 \mathrm{~m}$. Fig. 2 shows the area inside the inner fence. A commemorative obelisk is positioned at GZ, with the remains of the tower pillar still visible on the left. A close-up of the obelisk bearing a plaque is shown in Fig. 3. The Trinity site can be visited by the public twice a year, in April and October. The present-day dose rate at GZ from residual radioactivity is $0.5-1 \mathrm{mrem} / \mathrm{h}$.

Trinitite carries radionuclides of the Gadget debris that were volumetrically incorporated in the glass when it was molten. They are expected to remain intact because they are not subjected to possible surface reactions. Retention of the radionuclides is further aided by the arid climate of the desert. The radionuclides contained in Trinitite may include fission products from ${ }^{239} \mathrm{Pu}$ fission; activation products from neutron reactions with the nuclear fuel, the materials used in construction of Gadget, and the local GZ soil; the remnants of unburned nuclear fuel; as well as radionuclides of natural origin in the soil. Hansen and Rodgers (1985) reported a radiological survey of surface soil at the Trinity test site. However, only recently a quantitative $\gamma$-ray spectrometry of Trinitite glass has been reported by Schlauf et al. (1997).

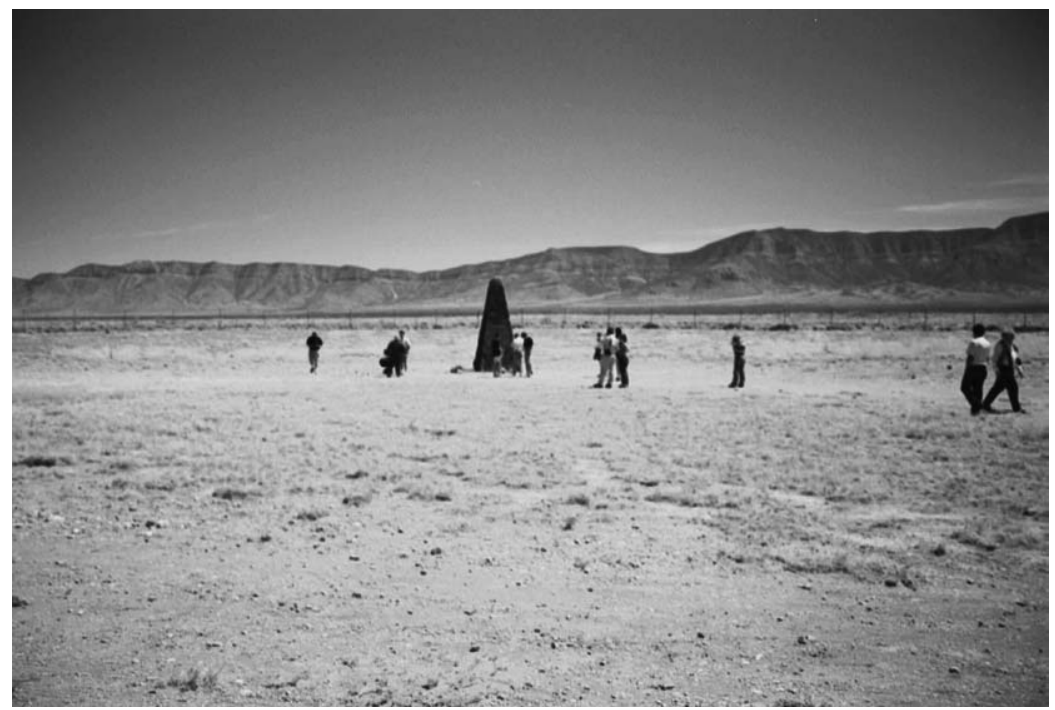

Fig. 2. Ground zero (GZ) at the Trinity test site. 


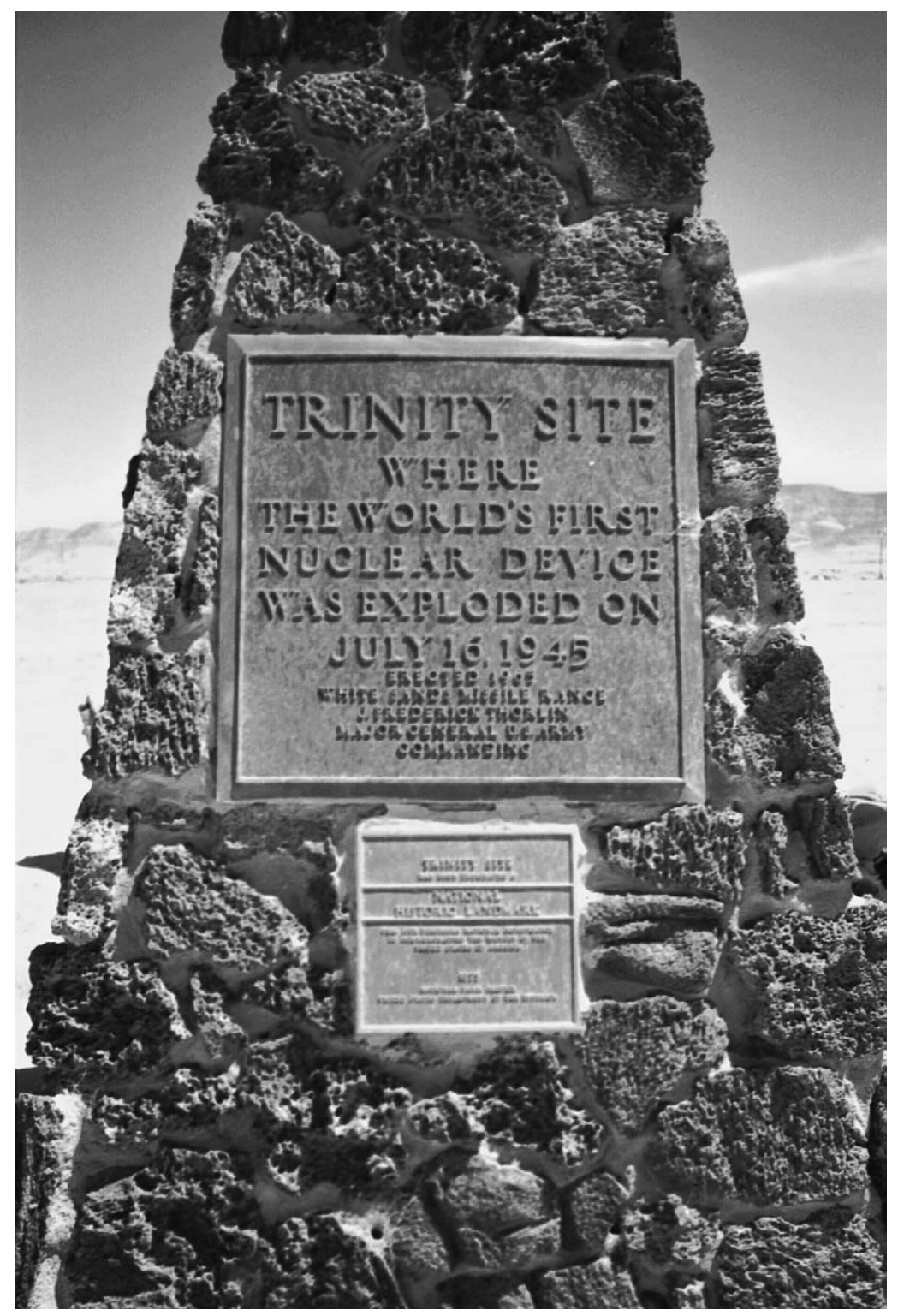

Fig. 3. Commemorative obelisk and plaque at GZ of the Trinity test site.

Our objectives of determining the radioactivity in Trinitite were three-fold: (i) research in environmental monitoring of manmade and natural radioactivity, which is a part of our laboratory function, (ii) determination of several radionuclides in Trinitite, which have not been reported in open literature, and (iii) bringing this historical event upon its upcoming 60th anniversary back to the modern 
environmental-radioactivity literature. Using combinations of radiochemistry, $\alpha$ spectrometry, $\gamma$ spectrometry, and $\beta$ counting, we carried out a detailed investigation of radioactivity in Trinitite. Preliminary results of this work have been reported elsewhere (Cooper, 2003; Parekh et al., 2004).

\section{Experimental}

\subsection{Samples of Trinitite}

Sixteen small pieces of Trinitite, with an aggregate mass of $8.362 \mathrm{~g}$ (designated as sample $\mathrm{A}$ in the present study), were obtained during a scientific tour to the Trinity test site organized by the American Nuclear Society in April 2002. The pieces were located 40-65 $\mathrm{m}$ from the position of the GZ tower, and thus represent a grab sample. Some individual pieces of this sample (Fig. 4) are mixtures of green glassy formations with small intrusions of the brown local soil. The samples, when monitored with radiation survey meters, exhibited appreciable $\alpha$ and $\beta / \gamma$ surface emissions.

Two additional pieces of Trinitite were purchased from the Mineralogical Research Company, San Jose, CA. These were single large pieces, weighing 6.221 and $8.598 \mathrm{~g}$ each. They were primarily shiny green glass material and were designated as samples $\mathrm{B}$ and $\mathrm{C}$, respectively (sample $\mathrm{C}$ is depicted in Fig. 5). The original locations of samples $\mathrm{B}$ and $\mathrm{C}$ are unknown.

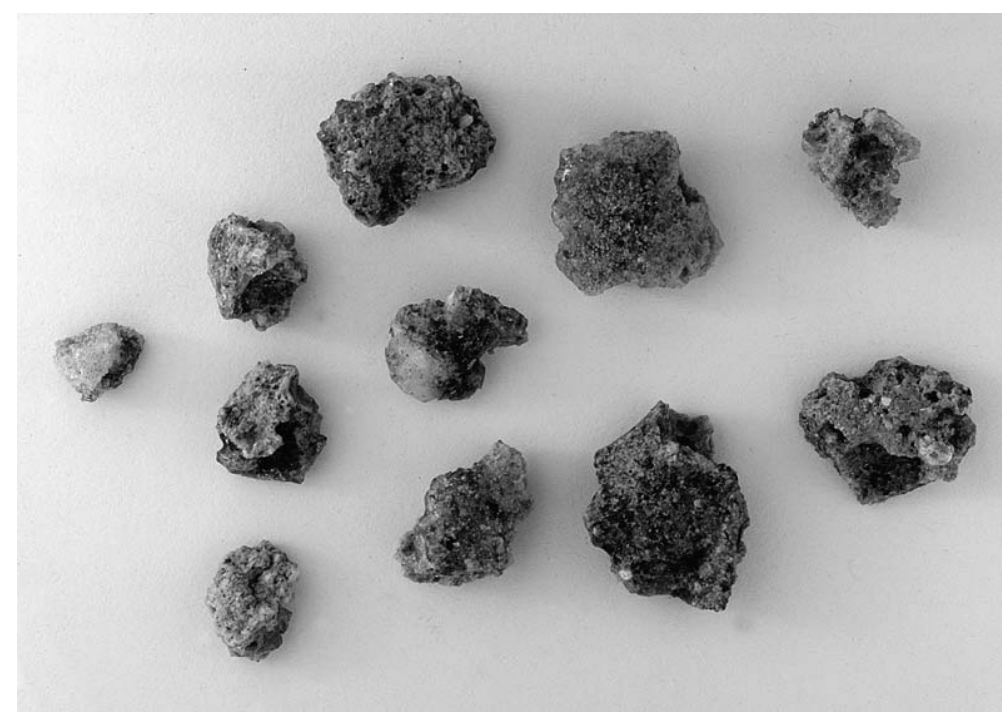

Fig. 4. Eleven of the 16 pieces of Trinitite comprising sample A. The individual diameters range from 0.5 to $1.5 \mathrm{~cm}$. 


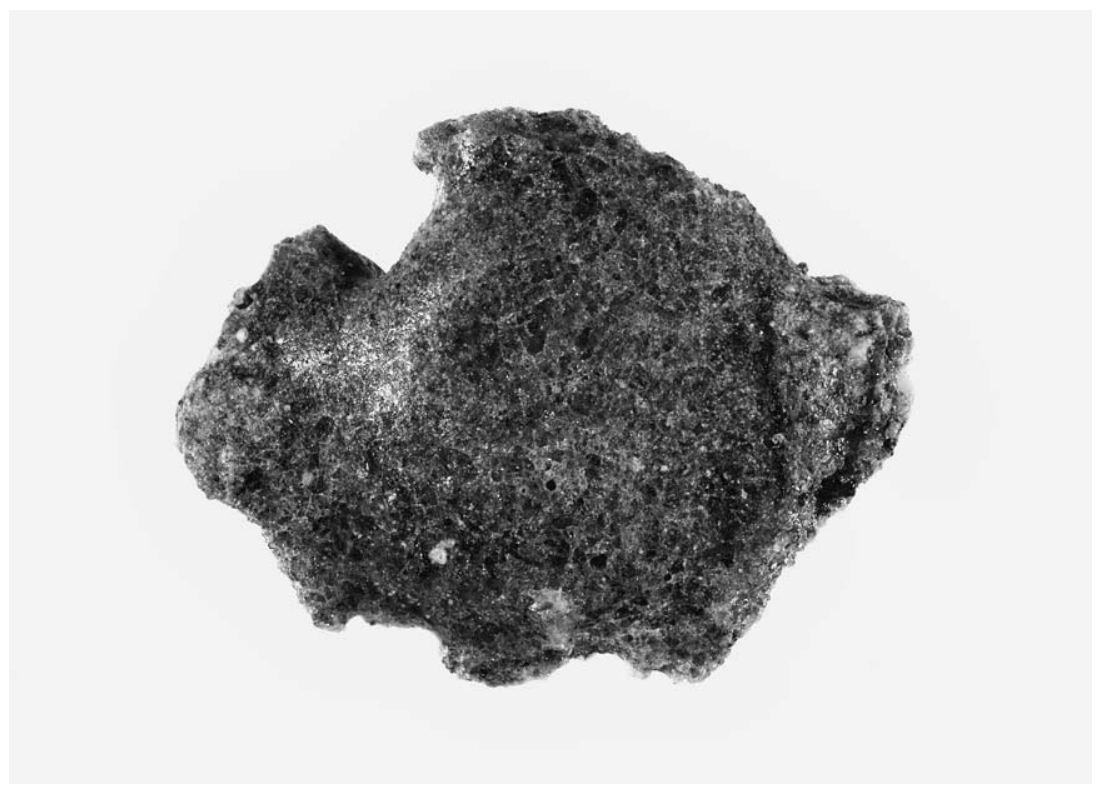

Fig. 5. Sample $\mathrm{C}$ of Trinitite. The maximum diameter is $4.0 \mathrm{~cm}$.

\subsection{Analytical procedures}

\subsubsection{Nondestructive analysis}

Fig. 6 shows a flow diagram of the various analytical steps along with the objectives of each analysis. Initially, a crude analysis was made on the intact samples for the presence of gross alpha (GA) and gross beta (GB) emitters. A few randomly selected pieces of sample A, weighing $5.369 \mathrm{~g}$ were counted on a $\alpha / \beta$ gas-proportional

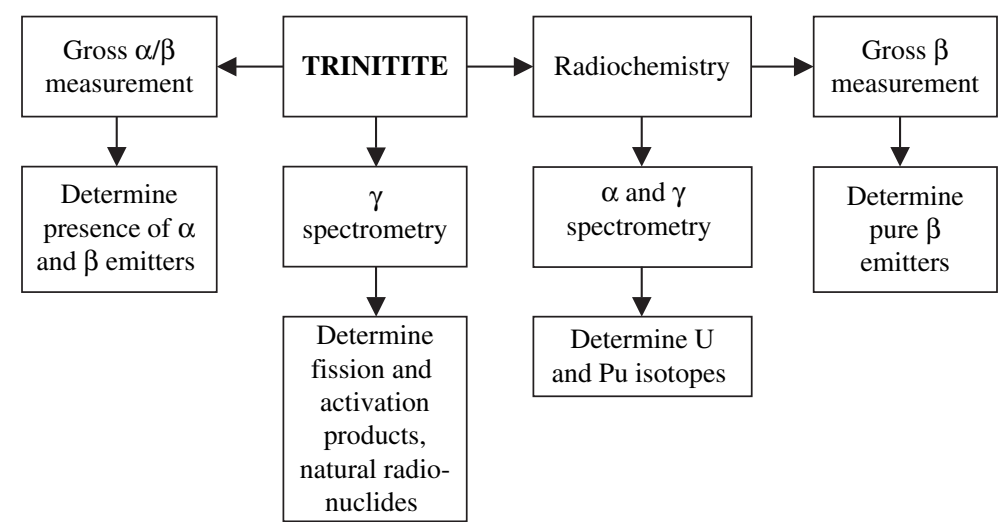

Fig. 6. Flow diagram of analytical procedures for Trinitite. 
counter. In addition, the aggregate sample A (16 pieces), and samples B and C were individually sealed in polyethylene bags and measured $\gamma$-spectrometrically. The measurements were conducted with the samples both on the face of a lowbackground, high-efficiency Ge detector as well as at a source-to-detector distance of $10 \mathrm{~cm}$ to minimize coincidence-summing losses. Counting times ranged from 4000 to $8000 \mathrm{~min}$.

\subsubsection{Radiochemical analysis}

Radiochemical analysis was performed on sample A only. The entire sample was ground in a steel-ball mill for $2 \mathrm{~h}$. The crushed sample was transferred to a screw-cap glass vial and homogenized using a Vortex. Analysis was done for the determination of $\mathrm{U}$ and $\mathrm{Pu}$ isotopes, as well as pure $\beta$ emitter ${ }^{90} \mathrm{Sr}$. Fig. 7 shows a flow diagram for the radiochemical procedures.

About $0.5 \mathrm{~g}$ aliquot of the ground sample was accurately weighed and transferred to a Teflon evaporating dish. Aliquots of concentrated $\mathrm{HNO}_{3}$ and $\mathrm{HF}$ were added to the sample, followed by the additions of known amounts of $\mathrm{Sr}^{2+}$ and $\mathrm{Fe}^{3+}$ carriers and ${ }^{85} \mathrm{Sr},{ }^{242} \mathrm{Pu}$, and ${ }^{232} \mathrm{U}$ tracers. The mixture was stirred, left overnight for digestion at room temperature, and then evaporated to dryness on a steam bath. The

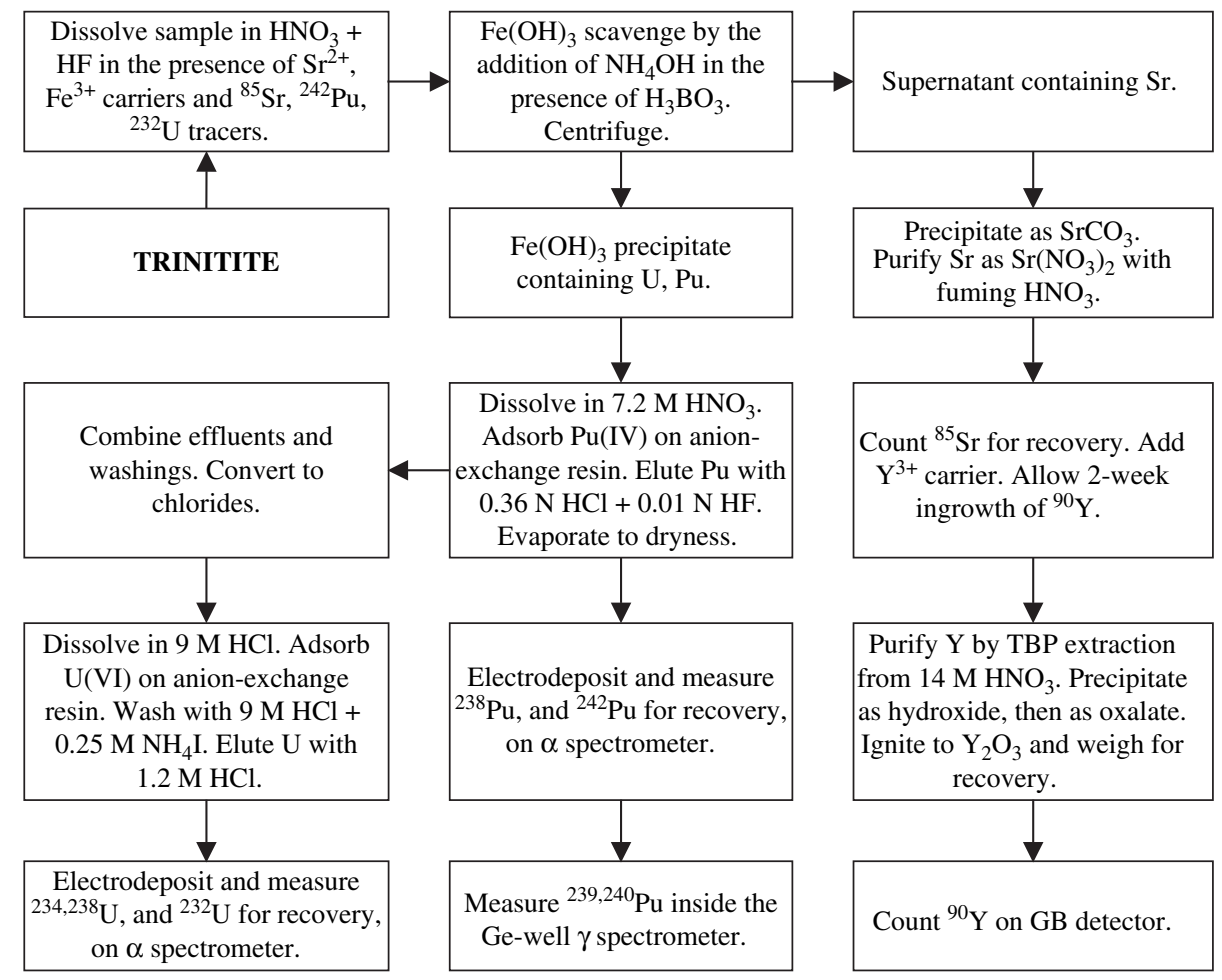

Fig. 7. Radiochemical procedures for the analysis of Trinitite. 
procedure of dissolution in an $\mathrm{HNO}_{3}+\mathrm{HF}$ mixture and subsequent evaporation was repeated three more times. The final residue was treated three times with concentrated $\mathrm{HNO}_{3}$ to drive off $\mathrm{HF}$ and to convert the residue to nitrates. Finally, a clear sample solution was obtained.

The actinides were scavenged from the sample solution with $\mathrm{Fe}(\mathrm{OH})_{3}$, and subsequently separated and purified on ion-exchange resin columns (see Fig. 7). After the separation, $\alpha$ emitters were electrodeposited on stainless-steel discs. The supernatant solution remaining after the $\mathrm{Fe}(\mathrm{OH})_{3}$ scavenging contained ${ }^{90} \mathrm{Sr}$, which was isolated and determined via its ${ }^{90} \mathrm{Y}$ daughter (Fig. 7).

\subsubsection{Nuclear instrumentation}

GA and GB measurements were made using a model XLB5 $\alpha / \beta$ gas-proportional counting system by Canberra, Inc., which has a typical background of $0.04 \mathrm{cpm}$ for $\alpha$ and $0.5 \mathrm{cpm}$ for $\beta$ (Semkow and Parekh, 2001).

Gamma-ray spectra were acquired using three Ge detectors (Canberra, Inc.): (1) a $100 \%$ efficient model GC10021 with a $2.1-\mathrm{keV}$ FWHM resolution at $1332-\mathrm{keV} \gamma$ energy; (2) a $131 \%$ efficient model GC13021 with a $2.0-\mathrm{keV}$ resolution (Semkow et al., 2002); and (3) a 60\% efficient model GCW6023S Ge-well detector. The well dimensions were $25 \mathrm{~mm}$ diameter and $41.5 \mathrm{~mm}$ depth, and the resolution was $1.2 \mathrm{keV}$ at 59.6-keV $\gamma$ energy (Parekh et al., 2004).

Alpha spectroscopy was performed using an Si detector model CE-400-100-22CM (Tennelec, Inc.), with a 400- $\mathrm{mm}^{2}$ active area, and a model TC256 alpha spectrometer.

\section{Results and discussion}

The GA and GB measurements indicated $8.25 \mathrm{~Bq} \mathrm{~g}^{-1}$ of $\alpha$ activity and 13.9 $\mathrm{Bq} \mathrm{g}^{-1}$ of $\beta$ activity in the sample. Due to self-absorption of $\alpha$ and, to a lesser extent, $\beta$ particles, these values reflect radiations emitted from the surface of the sample.

In a nuclear explosion, radioactivity arises from fission products of the $(\mathrm{n}, \mathrm{f})$ reaction, from activation products of the $(n, \gamma)$ reactions induced by fast (fission spectrum) and slow neutrons, as well as from the nuclear reactions such as $(n, 2 n)$ induced by fast neutrons. Because of the extremely high fluence of neutrons at the time of the explosion, product radionuclides from multiple-neutron-capture reactions $(2 n, \gamma)$ may also be present in the sample. In addition, Trinitite is likely to contain unfissioned fuel. The different pathways of inducing radioactivity in Trinitite are depicted in Fig. 8. In the following, we determine the reaction products from these pathways.

\subsection{Specific activities of radionuclides in Trinitite samples}

By direct measurement with $\gamma$-ray spectrometers, we could quantitatively determine several radionuclides. Fig. 9 shows a $\gamma$-ray spectrum of sample A, 


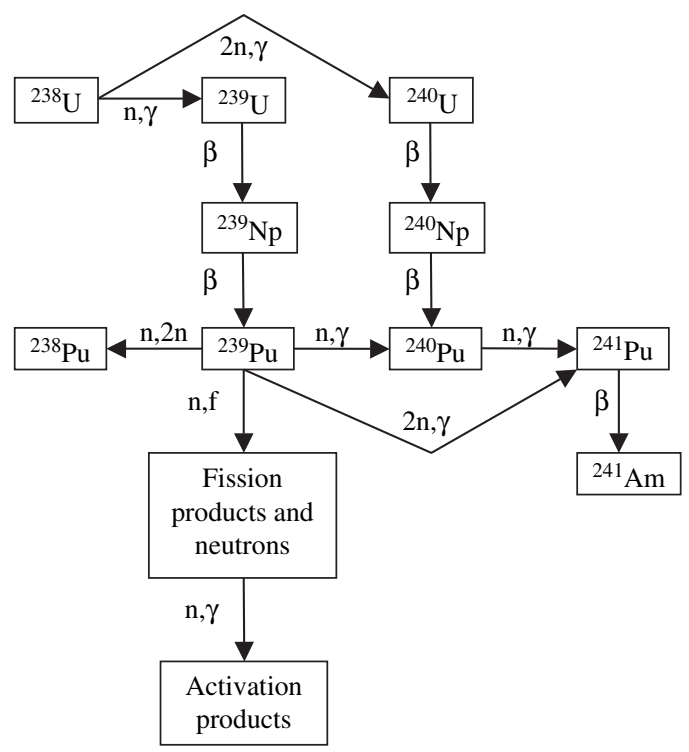

Fig. 8. Multiple pathways of radioactivity production in Trinitite.

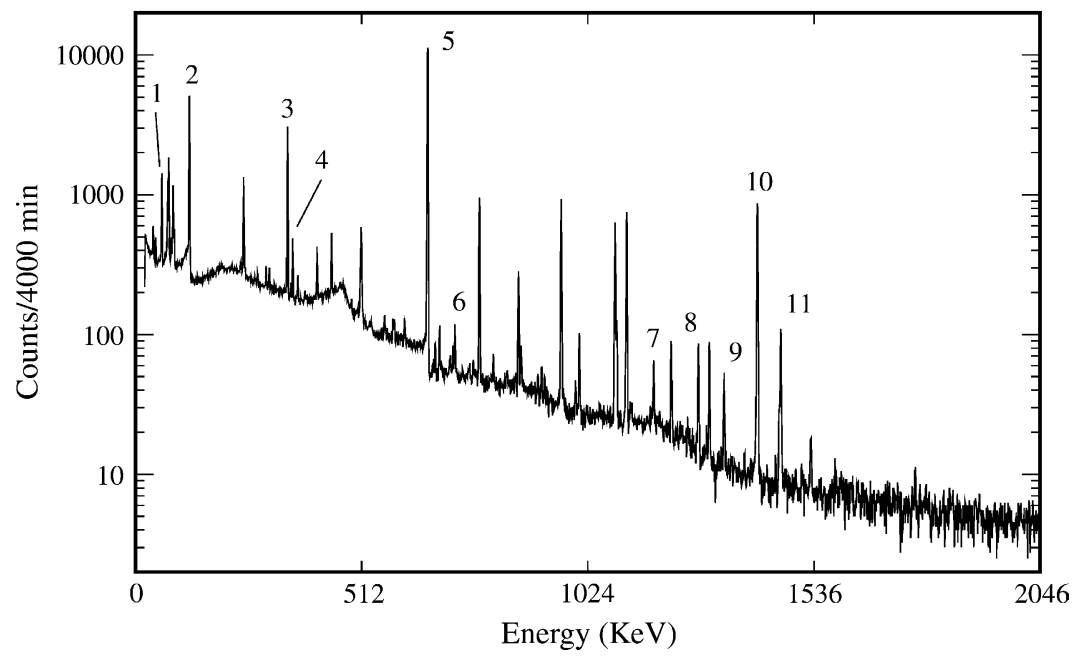

Fig. 9. Gamma-ray spectrum of Trinitite sample A measured on a $131 \%$ Ge detector at $10 \mathrm{~cm}$ distance. Selected peak assignments are as follows (measured energies are reported): (1) $59.4-\mathrm{keV}^{241} \mathrm{Am}$; (2) $121.7-\mathrm{keV}{ }^{152} \mathrm{Eu}, 122.8-\mathrm{keV}{ }^{154} \mathrm{Eu}$; (3) $344.2-\mathrm{keV}{ }^{152} \mathrm{Eu}$; (4) $356.0-\mathrm{keV}^{133} \mathrm{Ba}$; (5) $661.5-\mathrm{keV}{ }^{137} \mathrm{Cs}$; (6) 723.0-keV ${ }^{154} \mathrm{Eu}$; (7) $1173.4-\mathrm{keV}^{60} \mathrm{Co}$; (8) $1274.3-\mathrm{keV}^{152} \mathrm{Eu}$; (9) $1332.5-\mathrm{keV}^{60} \mathrm{Co}$; (10) $1407.8-\mathrm{keV}{ }^{152} \mathrm{Eu}$; (11) $1460.8-\mathrm{keV}^{40} \mathrm{~K}$. 
recorded by a high-efficiency Ge detector. Of the radionuclides detected, ${ }^{60} \mathrm{Co}$ is an activation product while ${ }^{137} \mathrm{Cs}$ is a fission product. Although ${ }^{133} \mathrm{Ba},{ }^{152} \mathrm{Eu}$, and ${ }^{154} \mathrm{Eu}$ are activation and fission products, they are 'shielded' by the corresponding stable isobars with $Z-1$, thereby blocking their cumulative fission yields through the $\beta$-decay chains. Neglecting the independent fission yields, which are very small (Wahl, 1988), we find that these three radionuclides were formed mainly as activation products through $(\mathrm{n}, \gamma)$ reactions. ${ }^{241} \mathrm{Am}$ is a decay product of ${ }^{241} \mathrm{Pu} ;{ }^{40} \mathrm{~K},{ }^{208} \mathrm{Tl},{ }^{212} \mathrm{~Pb}$, ${ }^{214} \mathrm{~Pb},{ }^{214} \mathrm{Bi}$, and ${ }^{228} \mathrm{Ac}$ are from natural radioactivity. Specific activities of several induced and natural radionuclides determined in the three samples $\mathrm{A}, \mathrm{B}$, and $\mathrm{C}$, as well as the results by Schlauf et al. (1997), are listed in Table 1. Specific activities of some of the radionuclides are in reasonable agreement with the samples, while others vary. Several radionuclides may have been subjected to fractionation in Trinitite, due to the differences in their boiling points (Glasstone and Dolan, 1977), or their activities may have been affected by a spatial variation of the neutron fluence.

The radionuclide ${ }^{60} \mathrm{Co}$ was an activation product of the ${ }^{59} \mathrm{Co}(\mathrm{n}, \gamma)$ reaction. The target nuclide ${ }^{59} \mathrm{Co}$ originated from the test-tower steel and from the GZ soil. Sample A reveals higher specific activity than those from samples B, C, and by Schlauf et al. (1997), which show similar activities. The variability seen in the specific activities of

Table 1

Specific activities of several radionuclides in various samples of Trinitite determined nondestructively by $\gamma$-ray spectrometry

\begin{tabular}{|c|c|c|c|c|c|}
\hline \multirow[t]{2}{*}{$\begin{array}{l}\text { Radio- } \\
\text { nuclide }\end{array}$} & \multirow[t]{2}{*}{$\begin{array}{l}\text { Half-life } \\
\text { (years) }\end{array}$} & \multicolumn{4}{|c|}{$\begin{array}{l}\text { Sample, specific activity normalized to the time of the explosion } \\
\left(\mathrm{Bq} \mathrm{g}^{-1}\right)\end{array}$} \\
\hline & & $\mathrm{A}^{\mathrm{b}, \mathrm{c}}$ & $\mathrm{B}^{\mathrm{c}, \mathrm{d}}$ & $\mathrm{C}^{\mathrm{c}, \mathrm{d}}$ & $\begin{array}{l}\text { Schlauf } \\
\text { et al. } \\
\text { (1997) }\end{array}$ \\
\hline \multicolumn{6}{|l|}{ Induced } \\
\hline${ }^{137} \mathrm{Cs}$ & 30.0 & $27.33 \pm 0.08$ & $66.51 \pm 0.13$ & $121.8 \pm 0.1$ & $90 \pm 9$ \\
\hline${ }^{133} \mathrm{Ba}$ & 10.54 & $7.55 \pm 0.45$ & $7.93 \pm 0.51$ & $9.80 \pm 0.26$ & $9.9 \pm 0.6$ \\
\hline${ }^{152} \mathrm{Eu}$ & 13.33 & $78.89 \pm 0.61$ & $22.61 \pm 0.38$ & $25.84 \pm 0.38$ & $27 \pm 1$ \\
\hline${ }^{154} \mathrm{Eu}$ & 8.8 & $16.1 \pm 1.3$ & $2.45 \pm 0.60$ & $2.74 \pm 0.67$ & $4.8 \pm 0.6$ \\
\hline${ }^{241} \mathrm{Am}$ & 432.7 & $1.841 \pm 0.053^{\mathrm{e}}$ & $2.446 \pm 0.049^{\mathrm{e}}$ & $4.137 \pm 0.058^{\mathrm{e}}$ & $2.9 \pm 0.5^{\mathrm{e}}$ \\
\hline${ }^{241} \mathrm{Pu}$ & 14.4 & $63.0 \pm 1.8^{\mathrm{f}}$ & - & - & - \\
\hline \multicolumn{6}{|l|}{ Natural } \\
\hline${ }^{232} \mathrm{Th}$ & $\begin{array}{l}1.271 \times 10 \\
1.405 \times 10^{10}\end{array}$ & $\begin{array}{l}0.822 \pm 0.011 \\
(2.88 \pm 0.35) \times 10^{-2}\end{array}$ & $\begin{array}{l}0.846 \pm 0.018 \\
(3.59 \pm 0.51) \times 10^{-2}\end{array}$ & $\begin{array}{l}0.741 \pm 0.015 \\
(2.75+0.35) \times 10^{-2}\end{array}$ & $\begin{array}{l}\mathrm{NR}^{\mathrm{g}} \\
\mathrm{NR}^{\mathrm{g}}\end{array}$ \\
\hline${ }^{238} \mathrm{U}$ & $4.468 \times 10^{9}$ & $(3.23 \pm 0.31) \times 10^{-2}$ & $(4.04 \pm 0.83) \times 10^{-2}$ & $(3.4 \pm 1.1) \times 10^{-2}$ & $\mathrm{NR}^{\mathrm{g}}$ \\
\hline
\end{tabular}

${ }^{\mathrm{a}}$ Uncertainties given are $1 \sigma$.

${ }^{\mathrm{b}}$ Sample A comprises 16 individual pieces with a total mass of $8.362 \mathrm{~g}$.

${ }^{c}$ The results are rounded off to preserve significant digits (maximum of four) for subsequent use in the equations.

${ }^{\mathrm{d}}$ Samples B and C are single pieces with respective masses of 6.221 and $8.598 \mathrm{~g}$.

e Present-day activity.

${ }^{\mathrm{f}}$ From ${ }^{241}$ Am ingrowth.

${ }^{\mathrm{g}}$ NR: not reported. 
${ }^{60} \mathrm{Co}$ may be due to decreased slow-neutron fluence with the distance from GZ and different sample locations. Applying this reasoning, it follows that sample A would have been located closest to GZ, while samples B, C, and the one studied by Schlauf et al. (1997), would have been located farther away.

The specific activities of fission product ${ }^{137} \mathrm{Cs}$ exhibit even greater variability than ${ }^{60} \mathrm{Co}$, but in an opposite direction (Table 1). ${ }^{137} \mathrm{Cs}$ is formed in fission predominately from $\beta$ decay of its short-lived precursors ${ }^{137} \mathrm{Xe}$ and ${ }^{137} \mathrm{I}$, and much less independently (Wahl, 1988). The cumulative ${ }^{239} \mathrm{Pu}$ fission yield for ${ }^{137} \mathrm{Cs}$ is $F_{137}=6.762 \%$ (Wahl, 1988). Xenon is a noble gas, iodine is very volatile, and cesium has a low boiling point $\left(671^{\circ} \mathrm{C}\right.$; Liede, 2003). Considering the immense heat of the explosion, the three elements would have dispersed in the gas phase. Upon condensation, the deposition of ${ }^{137} \mathrm{Cs}$ in Trinitite would be as cesium, and would strongly depend on the temperature. It is possible that samples located closest to GZ, where the temperature was the highest, would contain less ${ }^{137} \mathrm{Cs}$ than more distant samples. Since sample A revealed the lowest specific activity of ${ }^{137}$ Cs (Table 1), it was likely located closest to the explosion. This result is consistent with the ${ }^{60} \mathrm{Co}$ results.

The primary source of ${ }^{133} \mathrm{Ba}$, from ${ }^{132} \mathrm{Ba}(\mathrm{n}, \gamma)$ activation, was the Gadget device. Barium was a part of the explosive lens system, present as $\mathrm{Ba}\left(\mathrm{NO}_{3}\right)_{2}$ in a component called Baratol (Rhodes, 1986; Sublette, 2001). Reasonable constancy in the specific activities of ${ }^{133} \mathrm{Ba}$ in the three samples studied, as well as the sample investigated by Schlauf et al. (1997), can be seen in Table 1. This may be because this target was located very close to the fission reaction zone, and was subjected to semi-uniform neutron fluence. Moreover, the higher boiling point of barium than cesium $\left(1897{ }^{\circ} \mathrm{C}\right.$; Liede, 2003) made its deposition less susceptible to temperature variability.

The GZ soil was a source of the stable isotopes ${ }^{151} \mathrm{Eu}$ and ${ }^{153} \mathrm{Eu}$ for their $(\mathrm{n}, \gamma)$ activation to ${ }^{152} \mathrm{Eu}$ and ${ }^{154} \mathrm{Eu}$, respectively. The ${ }^{152} \mathrm{Eu}$ and ${ }^{154} \mathrm{Eu}$ specific activities in samples B and C are similar to those reported by Schlauf et al. (1997). However, they are 3-6 times lower than that found in sample A. The ratios of ${ }^{152} \mathrm{Eu}$ to ${ }^{154} \mathrm{Eu}$ activities are in reasonable agreement with all samples. The variability seen in the specific activities of ${ }^{152} \mathrm{Eu}$ and ${ }^{154} \mathrm{Eu}$ may be due to decreased slow-neutron fluence with distance from GZ and different sample locations. This trend is consistent with the enhanced activation of the soil component in sample A, located closer to GZ, similarly to ${ }^{60} \mathrm{Co}$.

Specific activities of natural radionuclides: ${ }^{40} \mathrm{~K},{ }^{232} \mathrm{Th}$, and ${ }^{238} \mathrm{U}$ in samples $\mathrm{A}, \mathrm{B}$ and $\mathrm{C}$ are comparable to within experimental errors (Table 1), indicating a semiuniform distribution. ${ }^{232} \mathrm{Th}$ was assayed using a $911.2 \mathrm{-keV} \gamma$ peak from ${ }^{228} \mathrm{Ac}$, whereas ${ }^{238} \mathrm{U}$ using a $351.9-\mathrm{keV} \gamma$ peak from ${ }^{214} \mathrm{~Pb}$. The presence of natural radionuclides in Trinitite was noted by Schlauf et al. (1997), but the activities were not reported. Potassium, a major element of the sand, presumably was distributed uniformly in the melt before solidification. The mean specific activity of ${ }^{40} \mathrm{~K}$ reported for surface soil samples at $\mathrm{GZ}$ was $0.89 \pm 0.16 \mathrm{~Bq} \mathrm{~g}^{-1}$ (Hansen and Rodgers, 1985) in agreement with the results of the current study. This agreement supports the contention of a uniform distribution of potassium during melting. In terms of natural potassium, these samples contain 2.65, 2.73 and $2.39 \%$ potassium, respectively, values that are close to $2.59 \%$ reported for the crustal average (Mason, 
1966). The reported mean for Th specific activity in GZ surface soil samples is $(3.2 \pm 0.1) \times 10^{-2} \mathrm{~Bq} \mathrm{~g}^{-1}$ (Hansen and Rodgers, 1985), close to the value for the crustal average of $2.9 \times 10^{-2} \mathrm{~Bq} \mathrm{~g}^{-1}$ (Mason, 1966). Our results for $\mathrm{Th}$ in Trinitite samples $\mathrm{A}, \mathrm{B}$ and $\mathrm{C}$ are comparable.

The results of the radiochemical analysis of sample A are given in Table 2 for six radionuclides. Deposition of the fission product ${ }^{90} \mathrm{Sr}\left(F_{90}=2.165 \%\right.$; Wahl, 1988) in Trinitite is expected to be higher than ${ }^{137} \mathrm{Cs}$ (Glasstone and Dolan, 1977) because strontium is less volatile with the boiling point of $1382{ }^{\circ} \mathrm{C}$ (Liede, 2003). In addition, short-lived ${ }^{90,90 \mathrm{~m}} \mathrm{Rb}$, the immediate precursors of ${ }^{90} \mathrm{Sr}$ in fission (Wahl, 1988), with the boiling point of $688{ }^{\circ} \mathrm{C}$ (Liede, 2003), can also deposit and then decay to ${ }^{90} \mathrm{Sr}$ inside Trinitite. The ratio of ${ }^{90} \mathrm{Sr}$ to ${ }^{137} \mathrm{Cs}$ deposition fractions $D$ in sample A of Trinitite is given by

$$
\frac{D_{90}}{D_{137}}=\frac{A_{90} T_{90} F_{137}}{A_{137} T_{137} F_{90}},
$$

where $A$ is the specific activity, $T$ is the half-life, and $F$ is the cumulative fission yield. Using the data from Tables 1 and 2, as well as from Wahl (1988), we obtain the ratio of 6.37 .

The radiochemically determined ${ }^{238} \mathrm{U}$ specific activity in sample A $\left(3.47 \times 10^{-2} \mathrm{~Bq} \mathrm{~g}^{-1}\right.$; Table 2$)$ agrees with the direct $\gamma$-spectrometric measurement $\left(3.23 \times 10^{-2} \mathrm{Bqg} \mathrm{g}^{-1}\right.$; Table 1$)$, to within an experimental uncertainty. The radiochemical value is more reliable, however, since the $\gamma$-spectrometric one was resolved from the $\gamma$ peak superimposed on a high background seen in Fig. 9. The results in Table 2 indicate a radioactive equilibrium between ${ }^{238} \mathrm{U}$ and its progeny ${ }^{234} \mathrm{U}$, to within an experimental uncertainty. The reported average uranium specific activity in GZ surface soil of $(2.22 \pm 0.48) \times 10^{-2} \mathrm{~Bq} \mathrm{~g}^{-1}$ (Hansen and Rodgers, $1985)$ is equal to the crustal average of $2.22 \times 10^{-2} \mathrm{~Bq} \mathrm{~g}^{-1}$ (Mason, 1966). The activities, which we found in samples A, B, and $\mathrm{C}$ are higher (Tables 1 and 2). This could have been due to a contribution from the $120-\mathrm{kg}$ natural-uranium tamper used

Table 2

Radiochemical analyses of several radionuclides in sample A of Trinitite

\begin{tabular}{lllc}
\hline Radionuclide & $\begin{array}{l}\text { Half-life } \\
\text { (years) }\end{array}$ & $\begin{array}{l}\text { Detection } \\
\text { system }\end{array}$ & $\begin{array}{l}\text { Specific activity } \\
\text { normalized to the } \\
\text { time of the explosion } \\
\left(\mathrm{Bq} \mathrm{g}^{-1}\right)\end{array}$ \\
\hline${ }^{90} \mathrm{Sr}$ & & $\beta$ Counting \\
${ }^{234} \mathrm{U}$ & 28.5 & $\alpha$ Spectrometry & $58.7 \pm 1.2$ \\
${ }^{238} \mathrm{U}$ & $2.454 \times 10^{5}$ & $\alpha$ Spectrometry & $(3.65 \pm 0.14) \times 10^{-2}$ \\
${ }^{238} \mathrm{Pu}$ & $4.468 \times 10^{9}$ & $\alpha$ Spectrometry & $5.965 \pm 0.071$ \\
${ }^{239} \mathrm{Pu}$ & 87.74 & $\gamma$ Spectrometry & $86.3 \pm 2.7$ \\
${ }^{240} \mathrm{Pu}$ & $2.411 \times 10^{4}$ & $\gamma$ Spectrometry & $4.10 \pm 0.94$ \\
\hline
\end{tabular}

${ }^{\text {a }}$ Uncertainties given are $1 \sigma$.

${ }^{b}$ The results are rounded off to preserve significant digits (maximum of four) for subsequent use in the equations. 
in the Gadget device (Sublette, 2001), which evaporated in the explosion and a fraction of it deposited in Trinitite similarly to the unfissioned plutonium. Subtracting the last value from the value for sample A, we obtain the specific activity of $(1.25 \pm 0.14) \times 10^{-2} \mathrm{Bqg} \mathrm{g}^{-1}$ due to the U-tamper.

Results of the specific activities of plutonium isotopes are discussed in a separate section.

\subsection{Estimation of slow-neutron fluence at $G Z$}

During nuclear explosion at the Trinity site, the fission produced an instantaneous burst of fast (fission spectrum) neutrons, which then scattered, slowed down, and were captured within several seconds (Bainbridge, 1976). Below, we estimate the time integrated slow-neutron flux (the fluence) during the Trinity test at the location of sample A, using ${ }^{152} \mathrm{Eu}$ as a monitor. The principal source of europium was the local soil, and the mode of formation was via ${ }^{151} \mathrm{Eu}(\mathrm{n}, \gamma)$ reaction with a very high thermal-neutron activation cross-section $\sigma_{\text {th }}=5300 \mathrm{~b}$ (Brunfelt et al., 1977). Although the apportionment of the neutron fluence between slow and fast is not known at this location, the contribution of fast neutrons to the activation is small, and we assume that it can be approximated with the cadmium ratio for a nuclear reactor, $\mathrm{CR}=43$ (Brunfelt et al., 1977). The production of ${ }^{152} \mathrm{Eu}$ from the ${ }^{153} \mathrm{Eu}(\mathrm{n}, 2 \mathrm{n})$ reaction can be neglected, because of the relatively low cross-section of this threshold reaction (in the mb range). Since the time of neutron irradiation $t$ is much shorter than the ${ }^{152} \mathrm{Eu}$ half-life $T$, the induced specific activity $A$ of ${ }^{152} \mathrm{Eu}$ is given by

$$
A=\frac{\varphi_{\mathrm{th}} \sigma_{\mathrm{th}} t c a N_{\mathrm{A}} \ln 2}{(1-1 / \mathrm{CR}) M T},
$$

where $\varphi_{\text {th }}$ is slow-neutron flux $\left(\mathrm{n} \mathrm{cm}^{-2} \mathrm{~s}^{-1}\right), a$ is the ${ }^{151} \mathrm{Eu}$ isotopic abundance, $N_{\mathrm{A}}$ is the Avogadro number, and $M$ is the europium atomic mass.

We deduced the Eu concentration $c$ in the local soil from the $\mathrm{Yb}$ concentration in surface samples in southern New Mexico. We used the well-established fact in geochemistry that the rare-earth elements exhibit the same geochemical behavior and hence have the same relative distribution pattern in geological samples (Haskin et al., 1968). A plot of chondrite-normalized concentrations of rare-earth elements in geological materials of the earth versus the atomic number yields smooth curve, in which the heavy rare earths (Eu through $\mathrm{Lu}$, including $\mathrm{Yb}$ ) remain constant. $\mathrm{The} \mathrm{Yb}$ concentration of $3.5 \mathrm{ppm}$ in southern New Mexico was taken from Shacklette et al. (1971), while the concentrations of $0.069 \mathrm{ppm} \mathrm{Eu}$ and $0.200 \mathrm{ppm} \mathrm{Yb}$ in chondrites were taken from Haskin et al. (1968). The Eu concentration in the local soil at GZ was thus estimated as $c=(3.5 \times 0.069) / 0.200=1.2 \mathrm{ppm}$. It is equal to the mean concentration of $\mathrm{Eu}$ in the earth's crust (Mason, 1966). Supporting evidence to this comes from the observed concentrations of $\mathrm{K}$ and $\mathrm{Th}$ in Trinitite (reported by us) and GZ surface soil (reported by Hansen and Rodgers, 1985), all of which are closely 
comparable with the crustal average concentrations of Mason (1966), as discussed in the previous section.

Taking the specific activity $A=78.89 \mathrm{~Bq} \mathrm{~g}^{-1}$ from Table 1 , and other variables either given above or taken from tables, we calculated the slow-neutron fluence $\Phi_{\mathrm{th}}=\varphi_{\mathrm{th}} t\left(\mathrm{n} \mathrm{cm}^{-2}\right)$ from Eq. (2). The following values were obtained: $3.88 \times 10^{15}$, $1.11 \times 10^{15}, 1.27 \times 10^{15}$, and $1.33 \times 10^{15} \mathrm{n} \mathrm{cm}^{-2}$ for samples A, B, C, and by Schlauf et al. (1997), respectively.

Bainbridge (1976) reported slow-neutron fluences at the Trinity test site measured at distances of $300-500 \mathrm{~m}$ from the GZ tower. Plotting them as a function of distance $r$ on a $\log -\log$ scale produces an approximately straight line, suggesting power-law dependence. We fitted the Bainbridge data and obtained

$$
\Phi_{\text {th }}\left(\mathrm{n} \mathrm{cm}^{-2}\right)=5.55492 \times 10^{26} / r^{6.25748}(\mathrm{~m}) .
$$

An exponent of 2 for $r$ would indicate a spherical spread of the neutrons without attenuation. However, the exponent greater than 6 obtained indicates considerable attenuation and capture of neutrons.

Using Eq. (3), we extrapolated the fluence to the distances 40 to $65 \mathrm{~m}$ from the GZ tower, where the Trinitite sample A was located, corresponding to 50.3-71.8 m slant range from the Gadget position (taking into consideration the height of the tower of $30.5 \mathrm{~m}$ ). We obtained the neutron fluence range $1.35 \times 10^{15}-1.25 \times 10^{16} \mathrm{n} \mathrm{cm}^{-2}$. The fluence of $3.88 \times 10^{15} \mathrm{n} \mathrm{cm}^{-2}$ determined for sample A using the ${ }^{152} \mathrm{Eu}$ monitor falls close to the middle of this range.

\subsection{Isotopic composition of plutonium in Trinitite}

${ }^{239} \mathrm{Pu}$ is produced in a nuclear reactor through the ${ }^{238} \mathrm{U}(\mathrm{n}, \gamma)$ reaction. At the same time, small amounts of ${ }^{238} \mathrm{Pu},{ }^{240} \mathrm{Pu}$, and ${ }^{241} \mathrm{Pu}$ are also produced in situ via $(\mathrm{n}, 2 \mathrm{n})$, $(\mathrm{n}, \gamma)$, and $(2 \mathrm{n}, \gamma)$ reactions, respectively, by the ingrown ${ }^{239} \mathrm{Pu}$ (e.g., Sublette, 2001; see Fig. 8). Therefore, ${ }^{239} \mathrm{Pu}$ that is isolated from the spent fuel also contains ${ }^{238} \mathrm{Pu},{ }^{240} \mathrm{Pu}$, and ${ }^{241} \mathrm{Pu}$, albeit in small amounts. Of these three isotopes, ${ }^{240} \mathrm{Pu}$ has a relatively high rate of spontaneous fission that gives rise to neutron emission. This, in turn, would make the nuclear-weapon device hazardous and unpredictable because of the preinitiation of the trigger. Therefore, ${ }^{240} \mathrm{Pu}$ is considered a serious contaminant in nuclear weapons. A prerequisite in the production of weapon-grade plutonium is that the concentration of ${ }^{240} \mathrm{Pu}$ be $<7 \%$ by weight. The super-grade plutonium contains $<3 \%{ }^{240} \mathrm{Pu}$. A nuclear device is made from $\mathrm{Pu}$ extracted from low burn-up reactor fuel (short-term irradiation) so that the build-up of ${ }^{240} \mathrm{Pu}$ is low. Typical burn-ups in reactors producing weapons-grade $\mathrm{Pu}$ in the US were 600-1000 megawatts-days (MWD)/tonne (Sublette, 2001). During the Manhattan Project, however, the naturaluranium fuel in the Hanford production reactors received only about $125 \mathrm{MWD} /$ tonne exposures due to the urgency of wartime production (Rhodes, 1986). These facts led Sublette (2001) to conclude that Hanford reactors produced "...super-grade weapons plutonium $\left(0.9-1.0 \%{ }^{240} \mathrm{Pu}\right.$ and negligible amounts of other isotopes)." 
It follows that $\mathrm{Pu}$ isotopes, other than ${ }^{239} \mathrm{Pu}$, could have also been produced at the Trinity site during the explosion itself, according to the reactions depicted in Fig. 8. Spectrometric and radiochemical analyses of $\mathrm{Pu}$ isotopes were conducted in two aliquots of sample A to elucidate this. Plutonium was radiochemically separated as depicted in Fig. 7, and electrodeposited on two stainless-steel discs. ${ }^{238} \mathrm{Pu}$ was determined by $\alpha$ spectrometry of the discs. Its decay during the 58 years of time span (1945-2003) would not reflect significantly on the observed concentration of its $\alpha$-decay product ${ }^{234} \mathrm{U}$ (Table 2 ), because of the relatively long half-life of the latter. A $\gamma$-ray spectrometric method was developed to resolve the ${ }^{239} \mathrm{Pu}$ and ${ }^{240} \mathrm{Pu}$ specific activities. The two discs were measured inside the well of the Ge detector resulting in a $\gamma$-ray spectrum depicted in Fig. 10. It shows several characteristic peaks of ${ }^{239} \mathrm{Pu}$ and the one of ${ }^{240} \mathrm{Pu}$ at $45.2 \mathrm{keV}$ (measured at $45.4 \mathrm{keV}$, which was a major component of the triplet seen in Fig. 10). The intensities of the 51.6-keV (measured at $51.7 \mathrm{keV}$ ) and the $45.2-\mathrm{keV} \gamma$-ray peaks were used in the respective analyses of these two isotopes. The results are given in Table $2 .{ }^{241} \mathrm{Pu}$ was determined nondestructively by $\gamma$ spectrometry of its daughter ${ }^{241} \mathrm{Am}$ which has grown from the $\beta$ decay of the former. As a result, we have given only the present-day concentration of ${ }^{241} \mathrm{Am}$ in Table 1 . The $1.841 \mathrm{~Bq} \mathrm{~g}^{-1}$ of this ${ }^{241} \mathrm{Am}$ came from the decay of $63.0 \mathrm{~Bq} \mathrm{~g}^{-1}$ of ${ }^{241} \mathrm{Pu}$.

The specific activities of plutonium isotopes from Tables 1 and 2 were used to calculate the weight percentages of the isotopes in sample A of Trinitite, which are reported in Table 3. It is seen that $98.7 \%$ of plutonium weight was from ${ }^{239} \mathrm{Pu}$, while $1.28 \%$ from ${ }^{240} \mathrm{Pu}$. The $1.28 \%$ is slightly more than the $0.9-1.0 \%$ in the original plutonium fuel mentioned by Sublette (2001). These results confirm that the original

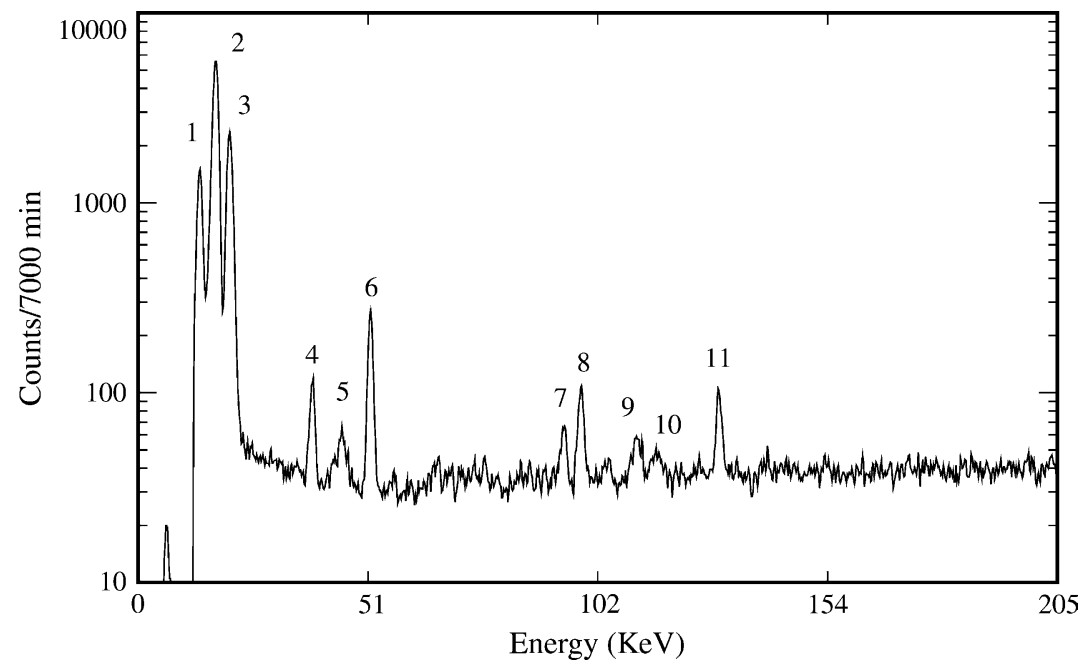

Fig. 10. Gamma-ray spectrum of Pu radiochemically separated from two 0.5-g aliquots of Trinitite sample $\mathrm{A}$ and measured on a $60 \%$ Ge-well detector. Peak assignments are as follows (measured energies are reported): (1) 13.9-keV U L ; (2) 17.3-keV U L $\beta$; (3) 20.4-keV U L ; (4) $38.8-\mathrm{keV}^{239} \mathrm{Pu}$; (5) $43.8-\mathrm{keV}^{238} \mathrm{Pu}^{2}$ 45.4-keV ${ }^{240} \mathrm{Pu}, 46.5-\mathrm{keV}{ }^{239} \mathrm{Pu}$; (6) $51.7-\mathrm{keV}{ }^{239} \mathrm{Pu}$; (7) 94.7-keV U K $\alpha_{2}$; (8) 98.5-keV U K ${ }_{\alpha 1}$, ${ }^{239} \mathrm{Pu}$; (9) 111.0-keV U K ${ }_{\beta 1}$; (10) 115.6-keV ${ }^{239} \mathrm{Pu}, \mathrm{U} \mathrm{K}_{\beta 2}$; (11) $129.3-\mathrm{keV}{ }^{239} \mathrm{Pu}$. 
Table 3

Isotopic composition of plutonium in Trinitite normalized to the time of the explosion

\begin{tabular}{llcl}
\hline Isotope & Methods used $^{\mathrm{a}}$ & Weight $^{\mathrm{b}, \mathrm{c}}(\%)$ & Source/site produced \\
\hline${ }^{238} \mathrm{Pu}$ & $\mathrm{RC} / \alpha$ spectrometry & $0.0247 \pm 0.0004$ & Explosion/GZ, NM \\
${ }^{239} \mathrm{Pu}$ & $\mathrm{RC} / \gamma$ spectrometry & $98.6509 \pm 3.0582$ & Reactor/Hanford, WA \\
${ }^{240} \mathrm{Pu}$ & $\mathrm{RC} / \gamma$ spectrometry & $1.2810 \pm 0.2922$ & Reactor/Hanford, WA; \\
& $\gamma$ Spectrometry & & Explosion/GZ, NM \\
${ }^{241} \mathrm{Pu}$ & $0.0434 \pm 0.0013$ & Explosion/GZ, NM \\
\hline
\end{tabular}

${ }^{\mathrm{a}} \mathrm{RC}$ : radiochemistry.

${ }^{\mathrm{b}}$ The derived quantities are rounded off so they add up to $100 \%$.

${ }^{\mathrm{c}}$ Uncertainties given are $1 \sigma$.

plutonium in the Gadget device exceeded the super-grade requirements, and that $0.28-0.38 \%$ of ${ }^{240} \mathrm{Pu}$ could have been produced in the Trinity explosion.

It is difficult to discern from the measured data that how much of ${ }^{238} \mathrm{Pu}$ and ${ }^{241} \mathrm{Pu}$ were produced at Hanford production plant and how much in the Trinity explosion, without the knowledge of the former. It has been reported by Rhodes (1986) that the Hanford plutonium was separated from uranium and fission products by the bismuth phosphate carrier, followed by a lanthanum fluoride carrier, and by oxidation of plutonium to transfer it to the solution. In this process, trivalent actinides, like Am, would have remained with the lanthanum fluoride carrier. Therefore, the ${ }^{241} \mathrm{Am}$ measured would reflect only on the ${ }^{241} \mathrm{Pu}$ which was produced at Hanford and did not decay during the production, as well as the one which was produced during the explosion. Nevertheless, considering the hereto confirmed ${ }^{240} \mathrm{Pu}$ content well exceeding the super-grade requirements, as well as the short burn-up cycles at Hanford production plant referred to by Rhodes (1986) and Sublette (2001), it is more likely that most of ${ }^{238} \mathrm{Pu}$ and ${ }^{241} \mathrm{Pu}$ were produced in the Trinity explosion rather than at Hanford.

Supporting evidence for the above results comes from the certified activities of ${ }^{239} \mathrm{Pu}$ and other radionuclides in standardized solutions, which are also produced in low reactor burn-up cycles. We procured ${ }^{239} \mathrm{Pu}$ standards from two sources: Isotope Products Laboratory (IPL), Burbank, CA, and the National Institute of Standards and Technology (NIST), Gaithersburg, MD. The weight percentages of ${ }^{238} \mathrm{Pu}$, ${ }^{239} \mathrm{Pu},{ }^{240} \mathrm{Pu}$, and ${ }^{241} \mathrm{Pu}$ were, respectively, $1.2 \times 10^{-4}, 99.9985,1.26 \times 10^{-3}$, and $9.0 \times 10^{-5}$ for the IPL standard, as well as $8.45 \times 10^{-4}, 99.2642,0.7263$, and $8.633 \times 10^{-3}$ for the NIST standard. These standards contain less ${ }^{238} \mathrm{Pu},{ }^{240} \mathrm{Pu}$, and ${ }^{241} \mathrm{Pu}$ than Trinitite. Although the standard-solution isotopic composition can be different from that of the weapons plutonium (standards could have been massseparated), it gives some supporting evidence that most of ${ }^{238} \mathrm{Pu}$ and ${ }^{241} \mathrm{Pu}$ in Trinitite could have been produced in the Trinity explosion.

\section{Summary and conclusions}

Three samples of Trinitite from the first nuclear-device test were analyzed for radioactivity. Sample A consisted of 16 pieces located $40-65 \mathrm{~m}$ from the position of 
GZ tower, while the locations of samples B and C are unknown. The techniques included radiochemistry in conjunction with $\alpha$ spectrometry, high-efficiency $\gamma$ spectrometry, and low-background $\beta$ counting. Specific activities were determined for fission products ${ }^{90} \mathrm{Sr}$ and ${ }^{137} \mathrm{Cs}$, activation products ${ }^{60} \mathrm{Co},{ }^{133} \mathrm{Ba},{ }^{152} \mathrm{Eu},{ }^{154} \mathrm{Eu}$, ${ }^{238} \mathrm{Pu}$, and ${ }^{241} \mathrm{Pu}$, the remains of the nuclear fuel ${ }^{239} \mathrm{Pu}$ and ${ }^{240} \mathrm{Pu}$, as well as natural radionuclides ${ }^{40} \mathrm{~K},{ }^{232} \mathrm{Th}$, and ${ }^{238} \mathrm{U}$ and their progeny.

The activities of ${ }^{60} \mathrm{Co}$ (from the steel tower and soil), ${ }^{152} \mathrm{Eu}$, and ${ }^{154} \mathrm{Eu}$ (both from soil) were found enhanced in sample A compared to samples B and C, which was attributed to the proximity of sample $\mathrm{A}$ to the explosion and higher neutron fluence. On the contrary, the activity of ${ }^{137} \mathrm{Cs}$ in sample A was depleted, presumably due to temperature-related fractionation. For the same reason, the deposition of ${ }^{90} \mathrm{Sr}$ in Trinitite was found 6.38 times larger than that of ${ }^{137} \mathrm{Cs} .{ }^{133} \mathrm{Ba}$ (from Baratol component of the Gadget device) was found distributed semi-uniformly in the samples, thus less subjected to fractionation. Our results for samples B and C generally agree with the results by Schlauf et al. (1997), however, they generally differ for sample A. The specific activities of ${ }^{40} \mathrm{~K}$ and ${ }^{232} \mathrm{Th}$ in Trinitite are similar for samples A, B, and C, and are comparable with the activities in the GZ soil determined by Hansen and Rodgers (1985). They are also comparable with the crustal averages by Mason (1966). ${ }^{238} \mathrm{U}$ was found distributed semi-uniformly in the samples also, however, was found enhanced relative to both the local soil and the crustal average. This enhancement of $1.25 \times 10^{-2} \mathrm{~Bq} \mathrm{~g}^{-1}$ was attributed to the natural-uranium tamper, which was a component of the Gadget device. Using ${ }^{152} \mathrm{Eu}$ as a monitor, the slow-neutron fluence of $3.88 \times 10^{15} \mathrm{n} \mathrm{cm}^{-2}$ was determined at the location of sample $\mathrm{A}$, which agrees with the extrapolation from neutron measurements reported by Bainbridge (1976). Isotopic analysis of plutonium in Trinitite revealed $98.7 \mathrm{wt} \%$ of ${ }^{239} \mathrm{Pu}$ and $1.28 \mathrm{wt} \%$ of ${ }^{240} \mathrm{Pu}$. These results confirm that $\mathrm{Pu}$ from the Hanford production plant, used in the first nuclear explosion, was of a super-grade quality. The slight enhancement of $0.28-0.38 \%$, over $0.9-1.0 \%$ of ${ }^{240} \mathrm{Pu}$ in the original fuel reported by Sublette (2001), may indicate some activation during the explosion. It is difficult to discern whether ${ }^{238} \mathrm{Pu}$ and ${ }^{241} \mathrm{Pu}$ in Trinitite were remnants from Hanford or were produced in the explosion. However, considering the low reactor burn-up cycles at Hanford, as well as higher contents of these isotopes in Trinitite than in plutonium standards, it more likely that most of ${ }^{238} \mathrm{Pu}$ and ${ }^{241} \mathrm{Pu}$ were produced in the explosion.

\section{Acknowledgements}

One of us (JC) acknowledges the support from the Ronald McNair PostBaccalaureate Achievement Program administered through the University at Albany, State University of New York. The assistance of E. Fielman in data processing is gratefully acknowledged. R. Lange is thanked for photography and image processing. 


\section{References}

Bainbridge, K.T., 1976. Trinity. Report LA-6300-H. Los Alamos Scientific Laboratory, Los Alamos.

Brunfelt, A.O., Roelandts, I., Steinnes, E., 1977. Some new methods for the determination of rare-earth elements in geological materials using thermal and epithermal neutron activation. J. Radioanal. Chem. $38,451-459$.

Cooper, J.M., 2003. Development of Methods for Gamma and Alpha Radioactivity Detection in Environmental Samples. Ronald McNair Post-Baccalaureate Achievement Program Report. University at Albany, State University of New York, Albany, NY.

Glasstone, S., Dolan, P.J., 1977. The Effects of Nuclear Weapons. US DOD and US DOE. US Government Printing Office: 1977 O-213-794, Washington, DC.

Hansen, W.R., Rodgers, J.C., 1985. Radiological Survey and Evaluation of the Fallout Area from the Trinity Test: Chupadera Mesa and White Sands Missile Range, New Mexico. Report LA-10256-MS. Los Alamos National Laboratory, Los Alamos.

Haskin, L.A., Wildeman, T.R., Haskin, M.A., 1968. An accurate procedure for the determination of the rare earths by neutron activation. J. Radioanal. Chem. 1, 337-348.

Liede, D.R. (Ed.), 2003. CRC Handbook of Chemistry and Physics, 84th ed. CRC Press, Boca Raton.

Mason, B.H., 1966. Principles of Geochemistry. J. Wiley \& Sons, New York.

Parekh, P.P., Semkow, T.M., Bari, A., Torres, M.A., Haines, D.K., Harris, P.R., Fielman, E.M., Kitto, M.E., 2004. Multifarious application of well-type germanium detector. J. Radioanal. Nucl. Chem. 262, 317-323.

Rhodes, R., 1986. The Making of the Atomic Bomb. Simon and Schuster, New York.

Ross, C.S., 1948. Optical properties of glass from Alamogordo, New Mexico. Am. Mineral. 33 (5, 6), 360-362.

Schlauf, D., Siemon, K., Weber, R., Esterlund, R.A., Molzahn, D., Patzelt, P., 1997. Trinitite redux: comment on "Determining the yield of the Trinity nuclear device via gamma-ray spectroscopy", by David Atkatz and Christopher Bragg (Am. J. Phys. 63, 411-413 (1995)). Am J. Phys. 65 (11), 1110-1112.

Semkow, T.M., Parekh, P.P., 2001. Principles of gross alpha and beta radioactivity detection in water. Health Phys. 81 (5), 567-574.

Semkow, T.M., Parekh, P.P., Schwenker, C.D., Khan, A.J., Bari, A., Colaresi, J.F., Tench, O.K., David, G., Guryn, W., 2002. Low-background gamma spectrometry for environmental radioactivity. Appl. Radiat. Isot. 57, 213-223.

Shacklette, H.T., Hamilton, J.C., Boerngen, J.G., Bowles, J.M., 1971. Elemental Composition of Surficial Materials in the Conterminous United States. Geological Survey Professional paper 574-D. US Government Printing Office, Washington, DC.

Storms, B., 1965. Trinity. The Atom 2 (8), 1-34.

Sublette, C., 2001. Nuclear weapons frequently asked questions. $<$ http://nuclearweaponarchive.org $>$.

Szasz, F.M., 1984. The Day the Sun Rose Twice. University of New Mexico Press, Albuquerque.

US DOE, 2000. United States Nuclear Tests July 1945 through September 1992. Report DOE/NV-209REV 15. US DOE. Nevada Operations Office, Las Vegas.

US GPO, 2000. Trinity Site July 16, 1945. US Government Printing Office: 2000-844-916, Washington, DC.

Wahl, A.C., 1988. Nuclear-charge distribution and delayed-neutron yields for thermal-neutron-induced fission of ${ }^{235} \mathrm{U},{ }^{233} \mathrm{U}$, and ${ }^{239} \mathrm{Pu}$, and for spontaneous fission of ${ }^{252} \mathrm{Cf}$. At. Data Nucl. Data Tables 39 (1), 1-156. Note: we use thermal-neutron-induced fission yields, in spite of the explosion was a fastneutron-induced fission, since the cumulative yields are comparable. 